ScIDice

\section{Prevalence of Dental Malocclusion among Male and Female Patients - An Institution Based Retrospective Study}

Research Article

\begin{abstract}
J Chandra Pooja ${ }^{1}$, Naveen Kumar $^{2 *}$, Ganesh Jeevanandan ${ }^{3}$
${ }^{1}$ Saveetha Dental College and Hospitals, Saveetha Institute of Medical and Technical Sciences, Saveetha University, Chennai-77, India.

${ }^{2}$ Senior Lecturer, Department Of Orthodontics and Dentofacial Orthopaedics, Saveetha Dental College and Hospitals, Saveetha Institute of Medical and Technical sciences, Saveetha University, Chennai-77, India.

${ }^{3}$ Reader, Department of Pedodontics, Saveetha Dental College, Saveetha Institute of Medical and Technical Sciences, Saveetha University, Chennai-77, India.
\end{abstract}

\title{
Abstract
}

\begin{abstract}
Malocclusion can be regarded as a condition affecting oral health, leading towards increment in dental caries, periodontal diseases, possible temporomandibular disorder (TMD), and psychosocial problems or other serious risks to oral health and hygiene. The early examination might also assist in the investigation and initiation of treatment during childhood, thus reducing the negative consequences on the health and well-being of patients. The knowledge of prevalence of dental malocclusion provides the clinician a better idea for treatment planning and to handle such patients. The aim of the study is to evaluate the prevalence of dental malocclusion among male and female patients in Saveetha Dental College. A retrospective study was carried out using case records of 16383 patients who reported to the Department of Orthodontics from June 2019 to March 2020. The prevalence of dental malocclusion among gender and age group were observed from the digital records and tabulated on a spreadsheet. The collected data was analysed by computer software SPSS version 21 using Chi square test with the level of significance with age and gender. The prevalence of various dental malocclusions were class I $(95.25 \%)$, class II $(3.87 \%)$ and class III $(0.89 \%)$. The prevalence of dental malocclusion showed significant association with age and gender.
\end{abstract}

Keywords: Dental Malocclusion; Periodontal Diseases; Temporomandibular Disorder.

\section{Introduction}

Malocclusion is an irregularity or malalignment of the teeth or a malrelationship of the dental arches beyond the range of what is accepted as normal [1]. Genetic environmental or a combination of both factors, along with various local factors such as adverse or deleterious oral habits can cause malocclusion [2]. The etiology of a malocclusion involves both genetic and environmental factors, and due to the possible geographic aspects in the distribution of malocclusion $[3,4]$.

Individuals with malocclusion develop a feeling of shame about their dental appearance and may feel shy and not confident in social situations or lose career opportunities [5]. Malocclusion also has a large impact on both individuals and society in terms of discomfort, quality of life and social and functional limitations $[6,7]$.
The prevalence of malocclusion in adults is a complex case that may be due to relapse of orthodontic treatment, dysfunctional treatment of children, loss of teeth or as a result of occlusion charges overtime[8-12].

Knowledge of prevalence of different types of dental and jaw anomalies is considered as the first step in the evaluation and treatment of their disorders. Many researches have been conducted for learning the prevalence of class I, class II, class II malocclusion. Occuring to the impact of environmental and genetic factors and role of geographic areas in dispersion of types of malocclusion indifferent countries, various distribution and prevalence of malocclusion have been reported [13].

Malocclusion has been a problem for some people from times immemorial, attempts to fix their problems can be traced back to at least 1000 years before Christ [14]. The benefits of orthodontic

\section{*Corresponding Author:}

Naveen Kumar,

Senior Lecturer, Department Of Orthodontics and Dentofacial Orthopaedics, Saveetha Dental College and Hospitals, Saveetha Institute of Medical and Technical sciences, Saveetha University, Chennai-77, India.

E-mail: naveenkumarm.sdc@saveetha.com

Received: October 25, 2019

Accepted: November 24, 2019

Published: November 25, 2019

Citation: J Chandra Pooja, Naveen Kumar, Ganesh Jeevanandan. Prevalence of Dental Malocclusion among Male and Female Patients - An Institution Based Retrospective Study. Int J Dentistry Oral Sci. 2019;S3:02:004:18-21. doi: http://dx.doi.org/10.19070/2377-8075-SI02-03004

Copyright: Naveen Kumar ${ }^{\circ} 2019$. This is an open-access article distributed under the terms of the Creative Commons Attribution License, which permits unrestricted use, distribution and reproduction in any medium, provided the original author and source are credited. 
treatment include improvement of physical function, prevention of tissue damage, and correction of aesthetic components [15, 16]. Similar studies on orthodontic management of dental malocclusion better self esteem confidence after successful orthodontic treatment [17-20].

Studies have shown the use of pendulum devices with mini-implants as anchorage unit has shown good results in the improvement of facial and dental esthetics, correction of Class II malocclusion, and no root resorption [21-23]. Patients having a skeletal and dental class III relationship, anterior open bite and posterior crossbite have been treated with camouflage orthodontics supplemented with the placement of mini-implants [24-26]. The aim of the study is to evaluate the prevalence of dental malocclusion among male and female population from the data available in the teaching institution.

\section{Materials and Method}

\section{Study design and Study setting}

The present study was conducted in a hospital in Chennai to evaluate the prevalence of dental malocclusion among male and female patients, from June 2019 to March 2020. The retrospective study was carried out with the help of case records of 76 patients who reported to the dental hospital for treatment. Since it is a retrospective study, carried out using patient case records, no informed consent was required from the patient. Ethical clearance to conduct this study was obtained from the Scientific Review Board of the hospital. All retrospective studies arising from the Data set between 01 June 2019 and 31 march 2020 will be covered by the following ethical approval number. SDC/SIHEC/2020/ DIASDATA/0619-0320.

\section{Sampling}

The type of study was Retrospective. The data of 16383 patients were reviewed and then extracted. Only relevant data was included to minimize bias. Non probability sampling method was carried out. Cross verification of data for errors was done with the help of clinical photographs. The study contained regional data generalised to the South Indian population.

\section{Data Collection}

A single calibrated examiner evaluated the case records of the 16383 patients from June 2019 to March 2020 and reviewed the prevalence of dental malocclusion among male and female patients. The following data were retrieved from the dental records: patient age and gender.

\section{Statistical Analysis}

The collected data was validated, tabulated and analysed with Statistical Package for Social Sciences for Windows, version 20.0 (SPSS Inc., Chicago, IL, USA) and results were obtained. Categorical variables were expressed in frequency and percentage; and continuous variables in mean and standard deviation. Chisquare test was used to test associations between categorical variables. Chi Square tests were carried out using demographic data like age and gender as independent variables and prevalence of dental malocclusion as the dependent variable. $\mathrm{P}$ value $<0.05$ was considered statistically significant.

\section{Result and Discussion}

A total of 16383 patients were included in the present study. Chisquare test was performed to analyse the significance between prevalence of dental malocclusion and age and gender.

Among the different types of dental malocclusion class I malocclusion was prevalent in 15,604 patients (95.25\%), class II malocclusion was prevalent in 634 patients $(3.87 \%)$ and class III was prevalent in 145 patients $(0.89 \%)$ and was the highest was class I which is followed by class II and class II malocclusion. (Figure 1) shows the frequency of patients having different types of malocclusions.

The percentage of patients under the age of 30 diagnosed with dental malocclusion were $45.77 \%$, patients between the age group of $31-50$ were $33.38 \%$ and patients above the age of 50 were $16.10 \%$ (Figure 2).

The study results (Figure 1) of shows that class I malocclusion is

Figure 1. The bar chart represents the percentage distribution of dental malocclusions. $X$-axis represents the types of dental malocclusion and the Y-axis represents the percentage distribution.Blue colour shows class I malocclusion, green colour shows class II malocclusion and beige shows class III malocclusion. Class I malocclusion was the most common among(95.25\%) other types of dental malocclusion.

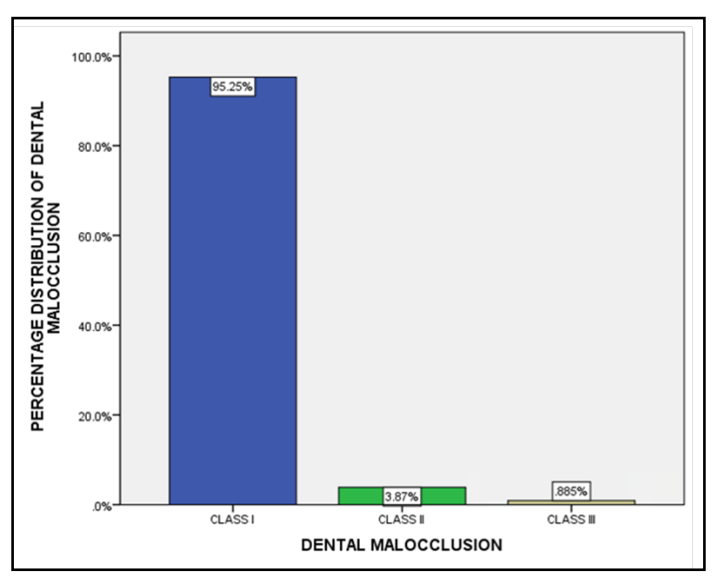


Figure 2. Bar chart represents the association of age and prevalence of dental malocclusion. $X$-axis represents the gender of the patient and Y-axis represents the number of patients with different types of dental malocclusions. Class I malocclusion(blue colour) was the highest among all the three age groups which was $45.77 \%$ below 30 years, 33.38\% between $31-50$ years and $16.10 \%$ above 50 years compared to class II(green colour) and class III(beige) malocclusions. Association between gender and prevalence of dental malocclusion were analysed with Chi-square test and it was significant $(P$ value -0.001$)$.

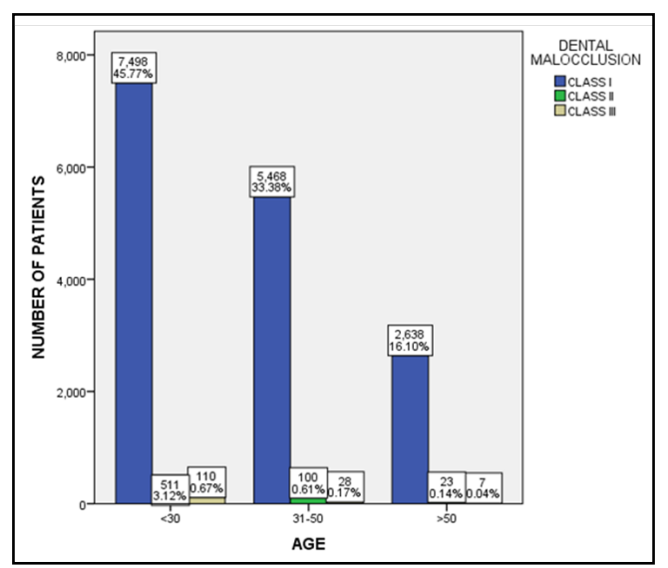

Figure 3. Bar chart represents the correlation of age and prevalence of dental malocclusion .X-axis represents the age of the patient and Y-axis represents the number of patients with different types of dental malocclusions. Class I malocclusion(blue colour) was the highest in both male $(54.98 \%)$ and female $(40.24 \%$ ) patients compared to class II(green colour) anf class III(beige) malocclusions. Association between age and prevalence of dental malocclusion were analysed with Chi-square test and it was significant( $P$ value -0.001$)$.

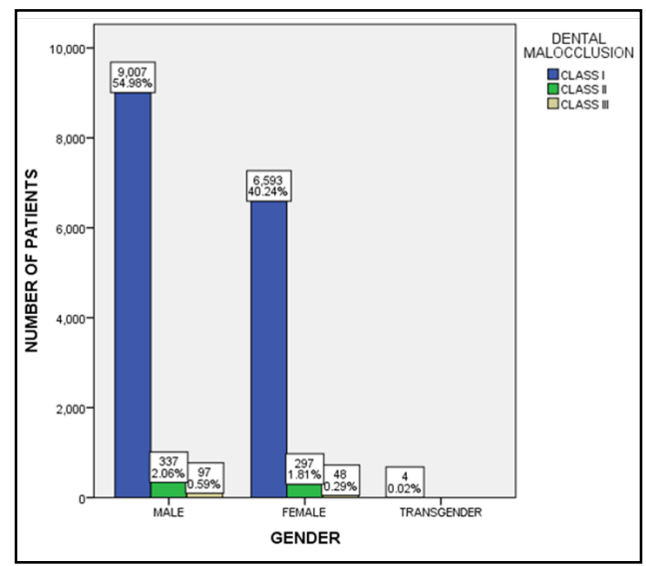

the highest compared to others which was similar to a study by Mridue Terehan et at [27] which shows angel's class I malocclusion-57.9\% which was more common than Angle's class II malocclusion [5.5\%] and similar to the group of Das et al [28]who reported $62 \%$ class I malocclusion and 7\% class II Div I malocclusion. The prevalence of class II Div II and class II malocclusion. The prevalence of class II Div 2 and class III malocclusion were low ie. $1.9 \%$ and $1.4 \%$. The study results of Magee Sultan Alhammadi et al [29] showed that in permanent dentition, the global distributions of Class I, Class II, and Class III malocclusion were $74.7 \%$ [31-97\%], 19.56\% [2-63\%] and 5.93\% [1-20\%], respectively. In mixed dentition, the distributions of these malocclusions were $73 \%$ [40-96\%], 23\% [2-58\%] and 4\% [0.7-13\%]. And concluded that worldwide, in mixed and permanent dentitions, Angle Class I malocclusion is more prevalent than Class II, specifically among Africans; the least prevalent was Class III.

The study results (Figure 2) shows that there was a significant association between age and prevalence of dental malocclusion ( $p$ value-0.001) and was most prevalent among the younger age group of below 30 years. The results of the study is similar to a study by Louis M Muwazi et al. [30] in the Ugandan population where the prevalence of malocclusion varied among different age groups as in children were $(n=696)$ and adults were $(n=396)$ according to study areas. Based on the districts, the prevalence of moderate to severe malocclusion varied between $6 \%$ and $14 \%$ in children and between $3 \%$ and 51 in adults.

The study results (Figure 3) shows that the percentage of female patients diagnosed with dental malocclusion was $42.3 \%$ and the male patients were $57.6 \%$. The study results show that there was a significant association between gender and prevalence of dental malocclusion( $p$ value-0.001) and was more prevalent among male patients. The study results are similar to the research by BorzabadiFarahani et al, [31] which stated that overbite, midline deviation, and crowding have a significant relationship with gender unlike overjet in the maxilla and mandible.

The study results were dissimilar to the results of Clarissa et al [32, 34] which said that in relation to sex, no statistically significant differences between males and females in prevelance to dental malocclusions and to a study by Kashif Aslam et al., [35] that said that there was no statistically significant difference was observed between prevalence of Angle's classification of malocclusion and the male and female patients (P value-0.118).

\section{Conclusion}

Within the limitation of the study it can be concluded that in 
the south Indian population class I was the commonest dental malocclusion followed by class II and III and was more prevalent among male patients in the younger age group, below 30 years of age. This was due to the change in the pattern of malocclusion in the past 60 to 70 years that malocclusion is seen more often in the younger generation. The knowledge and awareness about the prevalence of malocclusion will give a clear idea on where more focus must be implicated and lead to better treatment planning and outcome.

\section{Author Contribution}

Author 1 (J.Chandrapooja) carried out the retrospective study by collecting data and drafted manuscript performing the necessary statistical analysis. Author 2 (Dr.Naveen Kumar) aided in the conception of the topic, participated in the study design, statistical analysis and coordinated in developing the manuscript and author 3 (Dr.Ganesh Jeevanandhan) aided in coordinating and developing the manuscript. All the authors have contributed in developing the manuscript.

\section{Acknowledgement}

The authors would like to acknowledge the support of the department of Orthodontics and information technology of saveetha dental college and Hospitals and the management for their constant assistance with the research.

\section{References}

[1]. Mtaya M, Brudvik P, Astrøm AN. Prevalence of malocclusion and its relationship with socio-demographic factors, dental caries, and oral hygiene in 12- to 14-year-old Tanzanian schoolchildren. Eur J Orthod. 2009 Oct;31(5):467-76.Pubmed PMID: 19336630.

[2]. Viswanath A, Ramamurthy J, Dinesh SP, Srinivas A. Obstructive sleep apnea: awakening the hidden truth. Niger J Clin Pract. 2015 Jan-Feb;18(1):1-7. Pubmed PMID: 25511335

[3]. Rubika J, Felicita AS, Sivambiga V. Gonial angle as an indicator for the prediction of growth pattern. World J Dent. 2015;6(3):161-3.

[4]. Felicita AS, Chandrasekar S, Shanthasundari KK. Determination of craniofacial relation among the subethnic Indian population: a modified approach - (Sagittal relation). Indian J Dent Res. 2012 May-Jun;23(3):305-12. Pubmed PMID: 23059564.

[5]. Klages U, Bruckner A, Zentner A. Dental aesthetics, self-awareness, and oral health-related quality of life in young adults. Eur J Orthod. 2004 Oct;26(5):507-14.Pubmed PMID: 15536839.

[6]. Shivakumar KM, Chandu GN, Subba Reddy VV, Shafiulla MD. Prevalence of malocclusion and orthodontic treatment needs among middle and high school children of Davangere city, India by using Dental Aesthetic Index. J Indian Soc Pedod Prev Dent. 2009 Oct-Dec;27(4):211-8.Pubmed PMID: 19915271.

[7]. McLain JB, Proffitt WR. Oral health status in the United States: prevalence of malocclusion. J Dent Educ. 1985 Jun;49(6):386-97.Pubmed PMID: 3859517.

[8]. Jonsson T, Arnlaugsson S, Karlsson KO, Ragnarsson B, Arnarson EO, Magnusson TE. Orthodontic treatment experience and prevalence of malocclusion traits in an Icelandic adult population. Am J Orthod Dentofacial Orthop. 2007 Jan;131(1):8.e11-8.Pubmed PMID: 17208100.

[9]. Samantha C, Sundari S, Chandrasekhar S, Sivamurty G, Dinesh S. Comparative Evaluation of Two Bis-GMA Based Orthodontic Bonding Adhesives - A Randomized Clinical Trial. J Clin Diagn Res. 2017 Apr;11(4):ZC40ZC44.Pubmed PMID: 28571259.

[10]. Krishnan S, Pandian S, Kumar S A. Effect of bisphosphonates on orthodontic tooth movement-an update. J Clin Diagn Res. 2015 Apr;9(4):ZE01-5. Pubmed PMID: 26023659.

[11]. Kamisetty SK, Verma JK, Arun, Sundari S, Chandrasekhar S, Kumar A. SBS vs Inhouse Recycling Methods-An Invitro Evaluation. J Clin Diagn Res. 2015 Sep;9(9):ZC04-8.Pubmed PMID: 26501002.

[12]. Heikinheimo K, Nyström M, Heikinheimo T, Pirttiniemi P, Pirinen
S. Dental arch width, overbite, and overjet in a Finnish population with normal occlusion between the ages of 7 and 32 years. Eur J Orthod. 2012 Aug;34(4):418-26.Pubmed PMID: 21357654.

[13]. Krooks L, Pirttiniemi P, Kanavakis G, Lähdesmäki R. Prevalence of malocclusion traits and orthodontic treatment in a Finnish adult population. Acta Odontol Scand. 2016 Jul;74(5):362-7.Pubmed PMID: 26940248.

[14]. Staley RN. Etiology and prevalence of malocclusion. Textbook of orthodontics. 2001;83-96.

[15]. Mahesh Kumar P, Joseph T, Varma RB, Jayanthi M. Oral health status of 5 years and 12 years school going children in Chennai city--an epidemiological study. J Indian Soc Pedod Prev Dent. 2005 Mar;23(1):17-22.Pubmed PMID: 15858301

[16]. Ramesh Kumar KR, Shanta Sundari KK, Venkatesan A, Chandrasekar S. Depth of resin penetration into enamel with 3 types of enamel conditioning methods: a confocal microscopic study. Am J Orthod Dentofacial Orthop. 2011 Oct;140(4):479-85.Pubmed PMID: 21967934.

[17]. Soh J, Sandham A. Orthodontic treatment need in Asian adult males. Angle Orthod. 2004 Dec;74(6):769-73.Pubmed PMID: 15673139.

[18]. Felicita AS. Orthodontic management of a dilacerated central incisor and partially impacted canine with unilateral extraction - A case report. Saudi Dent J. 2017 Oct;29(4):185-193.Pubmed PMID: 29033530.

[19]. Dinesh SP, Arun AV, Sundari KK, Samantha C, Ambika K. An indigenously designed apparatus for measuring orthodontic force. J Clin Diagn Res. 2013 Nov;7(11):2623-6. doi: 10.7860/JCDR/2013/7143.3631.Pubmed PMID: 24392423.

[20]. Felicita AS. Orthodontic extrusion of Ellis Class VIII fracture of maxillary lateral incisor - The sling shot method. Saudi Dent J. 2018 Jul;30(3):265269.Pubmed PMID: 29942113.

[21]. Carvalho Ferreira FP, Barbosa Lima AP, de Paula EC, Ferreira Conti AC, Valarelli DP, de Almeida-Pedrin RR. Orthodontic Protocol Using Mini-Implant for Class II Treatment in Patient with Special Needs. Case Rep Dent. 2016;2016:1057263.Pubmed PMID: 27847652.

[22]. Sivamurthy G, Sundari S. Stress distribution patterns at mini-implant site during retraction and intrusion--a three-dimensional finite element study. Prog Orthod. 2016;17:4.Pubmed PMID: 26780464.

[23]. Vikram NR, Prabhakar R, Kumar SA, Karthikeyan MK, Saravanan R. Ball Headed Mini Implant. J Clin Diagn Res. 2017 Jan;11(1):ZL02-3.

[24]. Farret MM, Benitez Farret MM. Skeletal class III malocclusion treated using a non-surgical approach supplemented with mini-implants: a case report. J Orthod. 2013 Sep;40(3):256-63.Pubmed PMID: 24009326.

[25]. Felicita AS. Quantification of intrusive/retraction force and moment generated during en-masse retraction of maxillary anterior teeth using mini-implants: A conceptual approach. Dental Press J Orthod. 2017 SepOct;22(5):47-55.Pubmed PMID: 29160344.

[26]. Jain RK, Kumar SP, Manjula WS. Comparison of intrusion effects on maxillary incisors among mini implant anchorage, j-hook headgear and utility arch. J Clin Diagn Res. 2014 Jul;8(7):ZC21-4.Pubmed PMID: 25177631.

[27]. Trehan M, Chugh VK, Sharma S. Prevalence of malocclusion in jaipur, India. Int J Clin Pediatr Dent. 2009 Jan;2(1):23-5.Pubmed PMID: 25206094.

[28]. Das UM, Venkatsubramanian, Reddy D. Prevalence of malocclusion among school children in bangalore, India. Int J Clin Pediatr Dent. 2008 Sep;1(1):10-2.Pubmed PMID: 25206082.

[29]. Alhammadi MS, Halboub E, Fayed MS, Labib A, El-Saaidi C. Global distribution of malocclusion traits: A systematic review. Dental Press J Orthod. 2018 Nov-Dec;23(6):40.e1-40.e10. doi: 10.1590/2177-6709.23.6.40.e110.onl. Erratum in: Dental Press J Orthod. 2019 Aug 01;24(3):113.Pubmed PMID: 30672991

[30]. Muwazi LM, Rwenyonyi CM, Tirwomwe FJ, Ssali C, Kasangaki A, Nkamba $\mathrm{ME}$, et al. Prevalence of oral diseases/conditions in Uganda. Afr Health Sci. 2005;5(3):227-33.

[31]. Borzabadi-Farahani A, Borzabadi-Farahani A, Eslamipour F. Malocclusion and occlusal traits in an urban Iranian population. An epidemiological study of 11-to 14-year-old children. Eur. J. Orthod. 2009 Oct 1;31(5):477-84.

[32]. Fernandez CCA, Pereira CVCA, Luiz RR, Vieira AR, De Castro Costa M. Dental anomalies in different growth and skeletal malocclusion patterns. Angle Orthod. 2018 Mar;88(2):195-201.Pubmed PMID: 29215300.

[33]. Uslu O, Akcam MO, Evirgen S, Cebeci I. Prevalence of dental anomalies in various malocclusions. Am J Orthod Dentofacial Orthop. 2009 Mar 1;135(3):328-35.

[34]. Küchler EC, Risso PA, Costa Mde C, Modesto A, Vieira AR. Studies of dental anomalies in a large group of school children. Arch Oral Biol. 2008 Oct;53(10):941-6.Pubmed PMID: 18490001.

[35]. NADIM KA, RIZWAN S. Prevalence of angles malocclusion according to age groups and gender. Pak Oral Dental J. 2014 Jun 1;34(2). 